\title{
Chumy Chúmez, miembro de El Club de la Sonrisa
}

\author{
MARÍA RITA RodRÍGUEZ GARcíA \\ Universidad de Alicante
}

Resumen: Chumy Chúmez, seudónimo de José María González Castrillo, publicó en 1956 El manzano de tres patas y, dos años después, Mi tío Gustavo que en gloria esté. Ambas dentro de la colección de libros de humor El Club de la Sonrisa, de la editorial Taurus. Se trata de dos novelas singulares en la trayectoria del que fue conocido, sobre todo, por su labor como humorista gráfico. Por un lado, recogen ya todo el universo anímico del artista, por otro, hasta cierto límite, aún se adscriben en la línea directa que procede del humor del Otro 27. Analizaremos cada obra de forma independiente y en relación con el humor literario de la década de los cincuenta. De este examen extraeremos varias conclusiones, entre ellas la calidad literaria de Chumy Chúmez, parangonable a la de autores tan notables como Miguel Mihura o Rafael Azcona.

Palabras clave: Chumy, Chúmez, Club, Sonrisa, humor.

\section{Chumy Chúmez, a member of El Club de la Sonrisa.}

Abstract: Chumy Chúmez, pseudonym of José María González Castrillo, published in 1956 El manzano de tres patas and two years later, Mi tío Gustavo que en gloria esté. Both works included in the collection of humour books, El Club de la Sonrisa (The Smile Club), by the publishing house Taurus. This is about two unique works in the career of an author who was known, especially, for his task as a cartoonist. On the one hand, they cover this artist's entire universe of emotions, on the other hand, to some extent, they can be considered part of those belonging to the humour of the Spanish literary generation El Otro 27. Every work will be analysed independently and in connection with the 50's literary humour. Several conclusions will be drawn from this examination, such as the literary quality of Chumy Chúmez, comparable to other writers like Miguel Mihura or Rafael Azcona.

Keywords: Chumy, Chúmez, Club, Sonrisa, humour. 
El chiste para Freud, y para mí, [...] suele ser una agresión contra algo que nos prohibe algo, que puede ser el poder político o las costumbres.

(Chumy Chúmez, 2003:128).

\section{INTRODUCCIÓN}

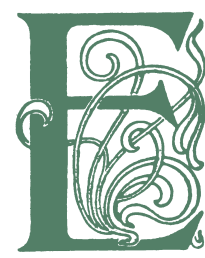

n la primera novela de Chumy Chúmez, El manzano de tres patas (1956), comienzan tocando a muerto. Todo el universo anímico de su autor, la muerte y la enfermedad, la rabia, la provocación, el humor negro ya está recogido en esta y en su siguiente novela, Mi tío Gustavo que en gloria esté (1958). Ambos títulos fueron publicados dentro de la colección El Club de la Sonrisa, serie de libros de humor editados por Taurus, desde abril de 1955 hasta los inicios de 1960. Obras de Miguel Mihura, Julio Camba, Ramón Gómez de la Serna y muchos más autores de similar categoría, compartieron cartel con Chumy Chúmez.

El estudio pormenorizado de estas dos obras de Chumy Chúmez se justifica, en principio, por su singularidad frente al resto de su obra. Se trata de las dos primeras novelas de un artista que hasta entonces había ejercido mayoritariamente de humorista y ante todo de humorista gráfico. Pero, además, están circunscritas de forma muy condicionada y concreta: en un espacio, una colección de obras, básicamente novelas de humor; y un tiempo, in medias res del franquismo, con todo lo que ello conllevaba en forma de represión, censura, y asfixia. Nuestro objetivo es analizar ambas obras individualmente a la par que en su relación entre ellas, con el resto de obras de la colección, con el humor del momento y con la posterior producción literaria de Chumy Chúmez.

Chumy Chúmez, el seudónimo de José María González Castrillo, se ha vuelto tan popular que ha invisibilizado su nombre real y otros sobrenombres que usó a lo largo de su carrera como simplemente Chumy, Don Claudio, Genovevo de la O o Equizyzeta. Nació en San Sebastián en 1927 y murió en Madrid en 2003. Trabajó de pintor, dibujante, periodista, escritor, conferenciante, tertuliano, guionista, director... Fue colaborador de La Codorniz, Triunfo o Madrid. Fundador y colaborador de la revista de humor Hermano 
$L o b o^{1}$. Entre sus obras más circunscritas a lo narrativo, además de las ya mencionadas, destacan: la autobiografía sobre sus recuerdos de la Guerra Civil, Yo fui feliz en la guerra (1986); Ser humorista (1988), una reflexión sobre su profesión; o las memorias póstumas, Vida de Maqueto (2003).

Colaboró como guionista en películas como Yo la vi primero (1974) dirigida por Fernando Fernán Gómez o en Mi mujer es muy decente, dentro de lo que cabe (1975, Antonio Drove), y para la televisión en el programa La tortuga perezosa (1963-1968). Fue director de dos películas: Dios bendiga cada rincón de esta casa (1977) y ¿Pero no vas a cambiar nunca, Margarita? (1978). Dirigió en 1982 el capítulo titulado «La lozana andaluza», de la, en aquel momento popular, serie Las pícaras. Junto a José Luis Coll o Antonio Mingote, fue contertulio en Este país necesita un repaso, programa de televisión que se emitió en la década de los noventa.

Recibió galardones como el Premio Paleta Agromán (1977), el Premio Mingote (1985), el de periodismo Francisco Cerecedo (1991) y el Premio de Humor Iberoamericano Quevedos (2002). Anteriormente, en 1970, le habían concedido el prestigioso Premio del Séptimo Salón del Humor Gráfico y la Caricatura en Canadá.

Nuestro autor participó, además de en la colección El Club de la Sonrisa, objeto prioritario de nuestro estudio, en otras series de obras de humor. $Y$ es que, especialmente tras la Guerra Civil, estas colecciones disfrutaron de varias décadas de esplendor. Se sucedían y superponían compitiendo en ocasiones entre ellas. En total fueron tres las colecciones dedicadas al humor que dirigió el editor José Janés: Al Monigote de Papel, El Club de la Alegría y Hostería del Buen Humor. De entre ellas, la primera fue la más duradera, desde 1942 hasta 1958. Otras colecciones con una manifiesta orientación ha-

1 Hermano Lobo (1972-1976) apareció en los kioscos por primera vez el 13 de mayo de 1972, con una portada firmada por Ops: un torero con la bandera americana a modo de capote. Su director fue durante los primeros años Ángel García Pintado, ya que el auténtico promotor, Chumy Chúmez no podía ostentar ese cargo al carecer del carnet de periodista, obligatorio entonces para ser director de una publicación. Manuel Summers fue el otro impulsor de la revista. Junto a estos autores colaboraron dibujantes como Ops, Forges, Gila o Perich y escritores como Luis Carandell, Cándido, Manuel Vicent, Francisco Umbral, Manuel Vázquez Montalbán, Eduardo Haro Tecglen, Tip y Coll, Antonio Burgos, Jimmy Giménez-Arnau o Rosa Montero. La revista que en un primer momento se iba a llamar El Huevo Duro, antes de que la censura lo impidiese, tuvo un éxito inmediato, convirtiéndose en la preferida de los universitarios, desbancando entre los lectores a La Codorniz, que se iba quedando anticuada. Las desavenencias con la empresa editorial, las discrepancias entre los colaboradores o la marcha de los más importantes de ellos a la competencia derrotaron a la publicación en solo cuatro años. 
cia el humor fueron El Lagarto al Sol, Buenas Noticias o El Gorrión. En la colección La Tortuga participó nuestro autor con Humor de contrabando (1959), obra de autoría doble junto a Miguel de Salabert. Además, los autores cómicos y las obras consideradas de humor proliferaban y hasta contaban en ocasiones con el prestigio de la crítica: Álvaro de Laiglesia o Noel Clarasó eran omnipresentes en las librerías, José Félix Tapia ganaba el Nadal en 1945 por su novela La luna ha entrado en casa y otra novela de humor, La úlcera de Juan Antonio Zunzunegui, ganó el Premio Nacional de Literatura en 1948. Aunque fueron años extremadamente fructíferos para el humor literario, la colección de la editorial Taurus fue de las que mayor éxito de público cosechó, llegando algunos de sus títulos a convertirse en superventas del momento. En relación con esto, Francisco Pérez González, uno de los fundadores de la editorial Taurus afirmaba: «Las cosas de humor funcionaban, al menos hasta la Transición, y nos diversificamos en esa dirección con el concurso de los humoristas de La Codorniz» (VV.AA. 2004: 16).

$\mathrm{Al}$ respecto es esencial conocer las poéticas del humor practicadas por los escritores de La Codorniz, puesto que al compartir nómina se extrapolarán desde el semanario hasta la colección El Club de la Sonrisa. El propio Miguel Mihura, primer director de la revista, desde 1941 hasta 1944, define el humor de La Codorniz (1941-1978) durante su etapa al frente, con los calificativos de inocente, absurdo y poético (Pueblo, 14-19-III-1960; apud González-Grano de Oro, 2004: 408). José A. Llera, al tratar el supuesto evasionismo del autor de Tres sombreros de copa, afirma: «El humor codornicesco se rebela contra todo tipo de formas esclerotizadas, sean literarias o morales. Su ambigüedad radica en que si bien no persigue una corrección al modo de la sátira y se sitúa en un marco ficticio deshistorizado, el reflujo irónico que recorre sus textos es propio de una obra abierta» (2007: 130). No obstante, la presencia de Álvaro de Laiglesia en la dirección tras dejar el puesto Mihura, va proporcionando a la revista un aire crítico cada vez más concreto. Chumy Chúmez publicó sus primeros dibujos en La Codorniz en 1947, por tanto pertenece a esta segunda etapa en que la sátira iba ganando terreno al humor deshumanizado, pero aún convivían ambos estilos.

En las obras de la colección El Club de la Sonrisa se recogerán ambas corrientes, dado que participarán autores de estilemas dispares. Nuestro autor será uno de los que tomen partido activamente por el camino de la rehuma- 
nización. La carga social, que se acrecentará en Chumy Chúmez conforme transcurran los años sesenta, ya se hace visible en las dos novelas aquí analizadas. Arremeterá igualmente, como ya se hacía en la etapa supuestamente evasionista, contra los tópicos y las costumbres queratinizadas, pero ahora las críticas serán más concretas y definidas. Por añadidura, en tanto el humor se torne especialmente negro, a base de truculencia y causticidad, la censura será más acre y el objeto de las reprensiones más manifiesto. En esta línea participarán otros colaboradores de La Codorniz, aunque cada uno con su peculiar estilo. Por ejemplo, Miguel Gila y Rafael Azcona.

Como miembro de El Club de la Sonrisa, Chumy Chúmez no solo hará las veces de novelista, también ejercerá de ilustrador. Es importante hacer constar con detalle su trabajo en este sentido por su profusa presencia durante los años en que estuvo la colección en las librerías. Realiza en solitario la portada de veintiuna obras, y junto a Lara² dibuja otras tres portadas más. Es decir, que de un total de 68 obras que se publicaron bajo el marbete de El Club de la Sonrisa nuestro autor elaboró, en solitario o en colaboración, más del $35 \%$. Chumy Chúmez fue, junto al humorista Antonio Mingote, uno de los dibujantes más prolíficos de la colección. En total hizo las portadas de los siguientes títulos: en 1955, Pepe, de Rafael Castellano, Papá mamá, la muchacha y yo, de Robert Lamoureux, Dos pequeños ejemplares, de Randal Lemoine, Olimpo, Siglo XX, de Juan Pablo Ortega, Don Venerando, de Carlo Manzoni, Un yanqui en autostop de Arthur Conte, La muela en la boca ajena, de Matthew Finch; en 1956, El hombre que no quería ser gangster, de Jean, Paul Lacroix; en 1957, Tejas y hombres, de Randal Lemoine, Don Clorato de Potasa, de Edgar Neville, Al asalto del Khili-Khili, de W. E. Bowman, Ni fuh ni fah, de Julio Camba, Antología del humor ruso y Antología del humor español; en 1958, Los jueves, milagro, novelización del film de Luis G. Berlanga y Antología del humor francés; en 1959, No os comáis las margaritas de Jean Kerr, 49 españoles en pijama y 1 en camiseta, de Evaristo Acevedo, La tasca de Tipsy de Rafael Castellano; y el último número de la colección y único publicado en 1960, Almanaque, 1960. Probablemente dibujó también la portada de su novela El manzano de tres patas, ya que, aunque la ilustración no va firmada, tiene su estilo en los motivos, la sensibilidad, el trazo y algunos leitmotiv de sus dibujos como eran los soles, tan generalizados que algunos investigadores lo consideran

2 Probablemente se trate de Antonio de Lara Gavilán, más conocido como Tono, aunque también usó entre otros el seudónimo Lara (Bauer, 2012). 
un seudónimo más. Además, junto a Lara ilustró: Papá, mamá, mi mujer y yo, de Robert Lamoureux, El doctor en el mar, de Richard Gordon y del mismo autor, Ánimo doctor.

Asimismo, confeccionó varias ilustraciones interiores. Junto a otros humoristas gráficos colaboró en Antología del humor español, Almanaque 1958 y Almanaque 1960. A la obra La vuelta al mundo de la risa, firmada por Pierre Daninos, aportó un dibujo a las numerosas ilustraciones de autores de todo el mundo. En solitario ilustró Las mil peores poesías de la lengua castellana, de Jorge Llopis. Y con profusión de dibujos, La tasca de Tipsy de Rafael Castellano. Especialmente interesantes son sus láminas para 49 españoles en pijama y 1 en camiseta, de Evaristo Acevedo, ya que, con su peculiar estilo, realiza numerosos retratos de personajes de renombre, no solo en la época del libro sino de algunos convertidos a día de hoy en clásicos atemporales. La nómina completa, que recogemos aquí dado el indudable interés, incluye: Gregorio Marañón, Pío Baroja, Antonio Casal, Azorín, Perico Chicote, Jacinto Benavente, Camilo José Cela, José María Pemán, Miguel Baez "Litri", doctor Blanco Soler, Celia Gámez, César González Ruano, Santiago Bernabeu, Rafael Rivelles, Gerardo Diego, Salvador Dalí, Cesáreo González, Luis Astrana Marín, Alfredo Marquerie, Domingo Ortega, Rafael Sánchez Ferlosio, Joaquín Calvo Sotelo, Pablito Calvo, José Camón Aznar, Luis Fernández Ardavín, Antonio Borrero "Chamaco", Sarita Montiel, Melchor Fernández Almagro, Bobby Deglané, Eduardo Aunós, Pepín Fernández, Luis Sagi-Vela, Agustín de Foxá, José Iturbi, Juan Manuel Lara, Carlos Arruza, Ramón Menéndez Pidal, Aurora Bautista, Ladislao Kubala, Julio Casares, el Marqués de la Valdavia, Eugenio Montes, Cristóbal Colón, XII Duque de Veragua, Matías Prats, Federico García Sanchiz, Daniel Vázquez Díaz, Luis Miguel Dominguín, Wenceslao Fernández Flórez y el Conde de Mayalde.

Volviendo a la creación puramente literaria, de entre todas las obras de Chumy Chúmez con un mayor componente narrativo, son las dos que publicó para Taurus las que mayor materia ficcional contienen. Aunque la presencia de elementos autobiográficos se dé en cierta medida, característica, por otro lado, inalienable a la poética de Chumy Chúmez, El manzano de tres patas y Mi tío Gustavo que en gloria esté están a años luz de otros títulos del autor vasco. Y es que en la mayoría de sus obras narrativas la autobiografía es el género predominante. Por ejemplo: en Yo fui feliz en la guerra (1986), la 
memoria se circunscribe a un período temporal cerrado, la Guerra Civil y la infancia del autor; en Vida de Maqueto (2003) los recuerdos transitan por todos los años de experiencia acumulados; y en otras como Ayer casi me muero (1988) o Cartas de un hipocondriaco a su médico de cabecera (2000), los límites son temáticos, centrándose la evocación en la enfermedad y la querencia de Chumy por la hipocondria. Sin embargo, aunque en El manzano de tres patas o en Mi tío Gustavo que en gloria esté protagonista y autor coincidan en anhelos o sufrimientos, lo cierto es que la historia no tiene la mayor parte de las características del género autobiográfico como son la modalización autorreflexiva, el tono confesional o el proceso rememorativo y es la fantasía del autor la que sustituye a sus vivencias.

\section{EL MANZANO DE TRES PATAS}

Según Fernán Escudero nuestro autor era asiduo lector de obras de «arte, filosofía o literatura, sobre ciencias humanas en general» al mismo tiempo «gustaba de estar al día en física, matemáticas, biología..., y lo reflejaba en su obra. Es bien conocida su pasión por la psiquiatría y la medicina en general» (Fernández Escudero, 2011: 110). En las dos novelas aquí analizadas, Chumy Chúmez dará cobertura a sus gustos y obsesiones.

En El manzano de tres patas incluso, el fundamento formal de la narración es la tríada de escuelas filosóficas helénicas: el cinismo, el estoicismo y el escepticismo. Las tres están recogidas en la novela a través del personaje principal y del narrador omnisciente. Chumy no hace una traslación erudita ni exacta de los postulados filosóficos. Toma lo que le interesa en cada caso para demostrar sus tesis. El protagonista encarna el estoicismo, un ser humano que ha anulado sus pasiones porque ante la adversidad ha decidido resignarse: «Fue quedándose petrificado en aquella ciudad egoísta» (1956: 29). A lo largo de la historia, asume que su estado es de imbecilidad y va a la búsqueda de la sabiduría, simbolizada en el cinismo, que promulgaba el ataque a las convenciones y el regreso a la naturaleza. Los paralelismos entre el protagonista y Diógenes de Sínope, maestro de la escuela cínica, son obvios, sobre todo cuando el protagonista cae a un tonel, la vivienda en la que el filósofo se obligaba a vivir para desprenderse de todo lo superfluo. La novela concluye, en el sentido filosófico, con el triunfo del escepticismo, el narrador exclama en 
las postrimerías de la historia: «iQuién sabe!» (1956: 172). El mismo Chumy, según su investigadora Fernández Escudero, «Fue [...] tildado de escéptico nihilista, de no respetar nada» (1956: 104). Las referencias clásicas no acaban aquí, tres de los personajes que rodean al protagonista tienen conexiones bufas con la religión romana, son Sabino, Penate y Jacinto.

Las conexiones literarias se establecen a través de contactos con La divina comedia de Dante: El empleo de alegorías como la del manzano, el uso del número tres, la bajada a los infiernos, la purificación de los pecados a través de los castigos, el ascenso al paraíso mediante la santidad alcanzada por la expiación, los cielos representados como una esfera.

Chumy comienza su primera novela, como ya hemos mencionado más arriba, haciendo referencia a La muerte. Usa la figura del presagio para adelantar el accidente mortal del protagonista. Esta cuestión no se limita al principio de la novela a modo de augurio, la recorre por toda la trama e incluso se convierte en otro personaje más, aunque solo sea en el mundo de lo onírico. Sin ir más lejos, la ciudad de provincias en la que habita el protagonista se distingue porque «huele a muerto» (1956: 29) y la muerte misma se le aparece al protagonista, aunque sin los oropeles macabros con que se la suele representar, ya que Chumy Chúmez la hace viajar en un medio tan prosaico como el tranvía. El mundo de los sueños es una vía más de transmisión de la historia. Los sueños son en ocasiones visiones alucinatorias provocadas por el alcohol o la calentura. Acude a las vías del subconsciente como otro cauce para exponer las tesis planteadas en la trama. Junto a los delirios, el autor utiliza numerosos formatos de narración, por ejemplo: chistes, diarios, manuscritos, canciones, cuentos.... Gran admirador de Freud, Chumy se valdrá del psicoanálisis para poner de manifiesto la represión moral que atenazaba a los oprimidos por el régimen nacionalcatólico.

El protagonista, el notario Carmelo Goena, en un principio «era un calzonazos de la vida, indiferente de puro resignado» (1956: 66). El autor lo define, además, por una mezcla de «gozo y aflicción» (1956: 9). Al enamorarse goza, pero a causa de su gazmoña instrucción también sufre ante el qué dirán, el posible alejamiento de la virtud o la caída en el vicio. El autor humilla al personaje mediante múltiples desdenes, como el uso de diminutivos, por ejemplo, Carmelito o «pequeño caballero notario» (1956: 55) o con apelativos como San Carmelito. «Se puso a pensar en su vida estúpida, ausente de 
problemas, vacía de pasiones», prosigue el autor acentuando la enfermiza propensión del protagonista hacia el goce por el sufrimiento. Está lleno de terrores: "Goena tenía un miedo tan grande metido en el alma por su fuga con Margarita, que empezó a llenarse de granos, como si su tradicionalmente honesta sangre protestase de su locura» (1956: 49).

La madre del protagonista es un ejemplar de madre devoradora, representa el régimen autoritario y castrante hasta la aniquilación $\mathrm{Al}$ padre ausente intenta sustituirlo por la figura del hijo; es posesiva y dominadora:

Su madre entró con su bolso, su boca sensual y vieja, sus medallas y su impertinencia cortés y disimulada. Besó a su hijo y saludó al médico con cortesía excesiva. luego se sentó en un sillón para escuchar, ver, juzgar y defender al hijo suyo y de su difunto esposo (1956: 11).

Y más adelante añade la madre con talante cristiano:

Este es el hijo de mis entrañas, que procede de una familia humilde y cristiana y sabe de cortesía mucho más que muchos marqueses. Este es mi hijo, el hijo de mis entrañas, que ha estudiado su carrera, ha ganado unas oposiciones y, además es bueno y obediente. Este es el hijo de mis entrañas, y que Dios le conserve aún muchos años en ellas (1956: 14).

La ironía se vuelve sarcasmo alcanzando en muchas ocasiones auténticos niveles de crueldad, como cuando encierran al notario para burlarse y ultrajarlo:

Ave María Purísima, dijo al comprender que estaba metido en un calabozo cuya única ventana daba a un patio interior, al parecer de gran altura. Cansado de esperar, empezó a gritar de nuevo. Rugió, pataleó, hasta que al fin, desesperado, hambriento y lleno de nuevos dolores, que aumentaban al menor movimiento, se tumbó mansamente en el suelo, que estaba hecho un asco por su vomitona (1956: 92).

Las torturas, para mayor escarnio, hasta se repiten exactamente iguales. Como el tonel en el que hace caer al protagonista, quien, para cuando puede liberarse, cae en otro igual, que además lleno de podredumbre. La novela hiere al lector, impidiéndole permanecer indiferente.

El humor, a diferencia de en la siguiente novela, no se consigue mediante malabarismos verbales. En la presente ocasión el autor se sirve de poner 
en evidencia la monstruosa necedad de la mayoría de los personajes. Por ejemplo, de una tal Adelina recuerda: «icon qué encantadora personalidad confundía una tabla flamenca con la dama de Elche!» (1956: 84).

Al igual que con la arnichesca señorita de Trevélez, los jóvenes asediados por el tedio de sus vacuas existencias, llenas de «hastíos indeterminados, de saludos corteses y de mudas limpias» (1956: 26), se guasean del personaje principal incapaz de soportar el peso de las risas de la opinión pública.

En tanto que las vejaciones, el dolor y la muerte absurda son constituyentes de la narración, la novela se aleja del humor y de la tónica general de la colección en la que está inserta, pero recoge ya con toda propiedad los rasgos que se convertirán en canónicos de la poética de Chumy Chúmez.

\section{MI TÍO GUSTAVO QUE EN GLORIA ESTÉ}

Tal vez por imposición de la editorial, tal vez por presiones económicas, si su libro anterior no se vendió tal y como se esperaba, lo cierto es que con su siguiente novela Chumy Chúmez incorpora mayor cuantía de recursos humorísticos de probada solvencia. Estas técnicas eran las que venía poniendo en práctica la revista La Codorniz, con éxito continuado durante muchos años, éxito que todavía perduraba a mediados de los cincuenta y que contaría con un vasto seguimiento otra década más. No obstante, Chumy, aunque otorga concesiones a los lectores, no pierde lo esencial de su poética, que por esos años ya tenía muchos elementos definidos que en el futuro solo se asentarían y perfeccionarían.

Esta obra fue merecedora del Premio Internacional Legión de Humor. El galardón surgió asociado a El Club de la Sonrisa. Se trataba de una parodia de premios como el Nadal, que tanto prestigio habían alcanzado tras la Guerra Civil. En esta farsa consciente de los premios literarios la dotación económica era de una peseta y se entregaba un simulacro de Óscar humorístico al que llamaban Monicaco de Escayola Imitando Bronce. La novela triunfadora, además, era publicada por Taurus. Los autores y las obras vencedoras fueron: 1955, Pepe, de Rafael Castellano; 1956, Lo malo de la guerra es que hace ipum!, de Jorge Llopis; 1957, iQue venga la bruja!, de Víctor Vadorrey; 1958, Mi tío Gustavo, que en gloria esté, de Chumy Chúmez; 1959, Este muerto es un 
pelmazo, de Domingo Medrano. Además de los citados premios, quedaron finalistas humoristas como José Luis Coll o Julio Penedo.

Mi tío Gustavo que en gloria esté es una parodia de biografía con ínfulas científicas. Trastoca, como suele ser el método habitual, los elementos canónicos del género, pero al incorporar también los rasgos propios de su poética, se elimina el mimetismo de las parodias de inferior calidad. La parodia será uno de los recursos más usados en El Club de la Sonrisa puesto que permitía una elaboración rápida, requisito común para este tipo de obras que generalmente se hacían bajo pedido y con urgencias.

Se incide, durante la narración, en una autenticidad imposible, en unos materiales inexistentes y en una repercusión fantástica. La ambigüedad en la autoría es un recurso humorístico esencial en la novela. Chumy Chúmez desaparece y se oculta tras un supuesto biógrafo, sobrino del protagonista, quien nos refiere el caso clínico del tío Gustavo. Paralelamente, incluye incisos con los comentarios de otros estudiosos en la materia, tales como el becario Ernesto Churriguerete, el académico Jaime Minglanilla o el investigador sueco Helmuttensen.

La metaliteratura es otro elemento significativo en el decurso narrativo. Las referencias a autores, obras o estéticas, ya tengan existencia real o sean producto de la ficción creada por Chumy, son abundantes, mencionándose, por ejemplo, a Françoise Sagan, Petrarca, el simbolismo o el surrealismo. El protagonista, por su parte, fue autor «del conocido ensayo "Mi admirado Nerón"» (1958: 17), y de opúsculos igualmente irreales como «sus famosas anotaciones sobre los maullidos de los gatos» (1958: 32), incluidos en sus obras completas, según su biógrafo, quien tiene a bien añadir un fragmento en una nota a pie de página. Los nombres de filósofos o de escuelas filosóficas, otra de las querencias del autor, aparecen a menudo, mencionándose a Hume, Descartes o, como familiarmente lo menciona Chumy, Pepe Ortega.

El protagonista se caracteriza precisamente por su escepticismo extremo. Así se le retrata: «Mi tío Gustavo no fue nunca guapo, es cierto, pero fue algo mejor: fue atractivo y descortés. Y además fue un escéptico jovial, alegre y despreocupado, a pesar de los dolores metafísicos que le roían el corazón» (1958: 19). Es un personaje repleto de matices, cambia conforme la existencia lo vence. Chumy Chúmez narra las derrotas de su vida hasta acabar conver- 
tido en «un vejete que correteaba dando zapatetas con su pierna paralítica y que se hacía sus heces, como finamente decía mi prima María, muerto de risa y en los momentos más inoportunos» (1958: 20). La última opinión que conservamos del protagonista al terminar la obra resulta desoladora: «Su tío era un imbécil» (1958: 159).

La obra está constituida básicamente por un gran cuerpo central ubicado en la segunda parte de la obra. Pero antes de entrar en materia el autor se dedica a introducir elementos, en ocasiones fuera de lugar, que aportan comicidad.

En primer lugar, tras una dedicatoria dirigida a «todos los jóvenes estudiosos que se alejen voluntariamente del pecado. Y a su sobrino Juan José», aparece una advertencia dirigida al lector con un estilo y un lenguaje deliberadamente arcaico que explota el recurso de la captatio benevolentiae, con su correspondiente falsa modestia y la consabida búsqueda de la predisposición favorable del lector. A continuación, el dibujo de un rudimentario árbol genealógico explicita las relaciones familiares. La carencia de complejidad del trazo del dibujo nos recuerda más a un diagrama para entender las leyes de la herencia que a un augusto retrato de las relaciones del protagonista. Más adelante, el lector conocerá las debilidades de carácter del padre del protagonista reforzando aún más la idea de la recesión genética. Después viene una nota aclaratoria sobre los personajes con una sucinta descripción de cada uno. Y, antes de entrar en materia, todavía ofrece el autor, en la primera parte, algunos antecedentes del relato posterior.

A su vez, dentro de la historia central, el autor dispone breves historias intercaladas, aún más desquiciadas, con personajes casi irreales a causa de sus deformidades y su acumulación en un breve espacio: «entre los que destacaba, por su personalidad, uno epiléptico e inmortal» (1958: 59) o «La cheposita (que) murió cuando fue madre, y el niño, dadas las condiciones físicas de la madre y las del padre, jornalero desnutrido, nació como si solamente fuese un dedo» (1958: 60).

El itinerario del protagonista, con su vuelta al mismo espacio del que salió en un principio, dota a la obra de circularidad. De esta forma, externamente la obra muestra un aparente, aunque peculiar orden. Sin embargo, el tiempo interno está descoyuntado. Comienza simultáneamente a la redacción del 
relato por parte del ficticio biógrafo, quien se remonta a sus primeros conocimientos directos del biografiado, que son en realidad casi el final de la novela. Paralelamente, en la justificación del relato, el autor distribuye anécdotas del protagonista sin orden ni concierto. A partir de ahí, tiene lugar el periplo vital del personaje principal, con una progresión más lógica, hasta regresar a un presente en que el biógrafo recaba datos para su investigación, rememorando de nuevo el pasado, concretamente la muerte de Gustavo. En última instancia, el narrador hace una propuesta hacia el futuro. El retorcimiento y fragmentación de la historia es deliberado. Se señala así, de forma más nítida, la caótica figura del tío Gustavo y su desquiciada mente.

La mirada del dibujante se aprecia en la disposición estática de algunas escenas, Chumy Chúmez ubica a los personajes describiendo su posición como si de en un lienzo o una viñeta se tratase.

España se expone en contraste con lo extranjero. Lo foráneo se muestra tan vehementemente maligno que la negatividad deviene en ironía. Hiperbólico resulta «inquina malsana de ciertas potencias extranjeras» (1958: 19).

Recursos herederos del Otro 27 son usados por Chumy Chúmez con cierta asiduidad, pero con su sello personal. Las metonimias y metáforas a las que la generación tan próxima a las vanguardias supo dar nuevo vigor mediante asociaciones extraordinarias, se revisten ahora de los temas y modos caros a la poética del autor vasco. Descienden así de sus pedestales de belleza hacia nuevas sociedades con elementos poco sublimes. Por ejemplo, «Los pechos son el espejo del alma» (1958: 53) o "Ya había caído la tarde, rompiéndose las narices contra el horizonte y manchando las nubes de sangre» (1958: 165). Igualmente, las comparaciones siguen la misma línea descendente: «La mujer del esteta, que tenía la boca como un higo chumbo [...] enrojecida, húmeda y blanda y unos bigotes valientes y encanecidos que nacían airosos y potentes como las agujas de las chumberas» (1958: 127).

Las interpelaciones del autor para dirigirse al lector proceden de las vanguardias. Se fuerza al público a ser partícipe de la creación artística. El lector, de esta manera, se incluye como un personaje más o como un colaborador del autor. Desde el mismo inicio de la obra el lector será incluido en el Club. Chumy Chúmez reforzará así las conexiones con el público. El uso de diferentes perspectivas para conocer la historia será otro recurso utilizado por 
el humor del Otro 27. Lo observamos en las diferentes autorías de la novela, de la que hemos tratado más arriba y en la búsqueda de testimonios directos sobre la vida del protagonista.

En relación con la ironía se sitúan figuras como las enumeraciones de una serie de términos relacionados, a los que sigue un elemento disconforme, el cual anula el objetivo explicativo, dotando a la gradación de comicidad. Además, se incorpora el extrañamiento ante un final no previsible. La sorpresa era otro recurso afín a las vanguardias. Por ejemplo: «Mi tío Gustavo desde niño estaba enamorado de algo que era su tía, su madre, su hermana, su esposa, una señorita frívola y la orquesta sinfónica de Boston» (1958: 47). Ejemplo del mismo tenor es la enumeración de obras científicas que se finiquita con la referencia a la artística composición: " “iAy, Gustavo, qué tiene tu trompa de eustaquio!" Revista musical en tres actos y veintidós cuadros, con música de los maestros Jierbabuena, Perejillo y Pajadó» (1958: 158). Este recurso era reiterativo en el humor del momento, tanto en la literatura como en el cine, donde se citaban revistas o cuplés con nombres similares, pero desvirtuados, extremosos y en consecuencia cómicos, como el cuplé Cóseme la faja del film La vida alrededor (Fernando Fernán Gómez, 1958) o la revista Morena y con ojeras de la que se escandalizaba el virtuoso Vicente, personaje de Rafael Azcona, famoso por la misma época.

En la misma línea encontramos algunos términos coordinados, que sin ser antitéticos no forman asociaciones habituales. Por ejemplo, la barca que pretende ser iniciática en el proceso de transformación del protagonista enuncia en su fe de bautismo los nuevos dogmas del cambio: «Progreso y castidad» (1958: 141). La crítica a la zarzuela también la encontraremos a menudo en estos humoristas. Mihura, Azcona y también Chumy abominarán del género chico. En esta obra se la califica de «funesta manía [...] nacional» (1958: 59).

La escatología es heredera directa del tremendismo de la literatura de los cuarenta, canon estético en declive, pero con presencia aún en la novelística de los cincuenta. Chumy Chúmez, dado su talante, su inclinación y su naturaleza, incorporó esta técnica desde sus inicios artísticos, cada vez con fines menos estetizantes, pero más lacerantes con los constituyentes nocivos que conforman el mundo que le ha tocado vivir. Indigentes con incontinencia o con flemas y ancianas con piernas ulceradas que cuidan sus llagas incurables con fervor malsano. Este último personaje, que en la presente novela es sólo 
secundario, resulta similar a la doña Martina de Azcona en El pisito, obra de un año antes a la que nos ocupa. Ambas son ancianas y comparten pústula. Esto demuestra un universo temático procedente de vivencias comunes. $E l$ pisito, además, se publicó por primera vez en la colección El Club de la Sonrisa, la misma de El manzano de tres patas y Mi tío Gustavo que en gloria esté.

Junto a estas figuras, el autor vasco recurre en escasas ocasiones a juegos de palabras, embebidos de una comicidad más banal, por su elementalidad o ante sus conexiones con una contemporaneidad tanto temporal como espacial que anula el universalismo que caracteriza su obra. La derivación «El señor de la perilla es un perillán» (1958: 127) o las referencias a las subvenciones de la Fundación March son ejemplos de ambos casos. Pero desde luego son poco abundantes en la valoración final de la obra.

Esta novela concluye con otra vuelta de tuerca. El protagonista tras su accidente, no muere, pero queda:

Con una disminución global de todos los rendimientos psíquicos. Carecerá de iniciativas y le desaparecerá la libido y la potencia sexual. ¿Eh? ¿Qué le parece la paradoja? Se va a buscar la soledad para vencer con la razón al cuerpo y la, al parecer, fuente de la razón le ayuda a conseguir sus fines de la manera más abyectamente biológica (1958: 143).

Mi tío Gustavo que en gloria esté nos recordará obras tan antibelicistas como Johnny cogió su fusil (1939), de Dalton Trumbo.

\section{CONCLUSIONES}

En cada novela aparecen la muerte, la enfermedad, el dolor, la humillación, revisitados con el espíritu burlón y macabro de Chumy Chúmez. El andamiaje de las dos obras se sustenta en similares cimientos y materiales. Una atmósfera opresiva y de delirio envuelve las historias. Escenas similares, alcohol como narcótico y paliativo para aniquilar el dolor ante la conciencia de la realidad, borracheras infinitas y exhaustas que acaban en tragedia. Enfermedades y dolencias se multiplican, el protagonista de El manzano de tres patas tiene el virus de la necedad, los personajes se accidentan, taras genéticas que exterminan familias. Los dos protagonistas sufren el mismo tipo 
de desgracia, un fortuito accidente fatal consistente en un golpe mortal en la cabeza. Tanto en su primera novela como en la siguiente, la crítica a la gazmoñería burguesa con sus costumbres anquilosadas y su pusilánime pudibundez es un eje en la obra. Y ante todo, en ambas novelas Chumy Chúmez arremete contra los que se han anulado a causa de un exceso de sacrificio o a fuerza de descreimiento y sobre todo ataca al entorno, a la instrucción aleccionadora que ha aniquilado el yo.

Con el cambio de dirección que hubo en la editorial Taurus, la colección El Club de la Sonrisa cerró sus puertas en los inicios de la nueva década de los sesenta. Con ella se clausuró para los humoristas un vehículo de expresión alternativo a La Codorniz, que además permitía un desarrollo de su humor en un contexto y con unas exigencias diferentes a las de una revista. $\mathrm{Al}$ mismo tiempo, con una coyuntura histórica marcada por el desarrollismo, nuevas formas de expresión como la televisión dirigieron a los humoristas hacia otras vías para desarrollar su labor. Se intensificó paulatinamente la crítica al sistema y un párvulo erotismo fue conquistando la mayor parte de las expresiones artísticas. La pérdida de interés por el humor tal y como hasta entonces había triunfado no fue instantánea, pero sí inevitable.

No podemos saber qué habría ocurrido de haber tenido nuestro autor la posibilidad de continuar inmediatamente su labor como novelista. Lo que sí conocemos con certeza es que sus dos primeras obras revelan una lucidez, una agudeza y una maestría, pocas veces vista en un novelista bisoño como era él. Las dos novelas de Chumy Chúmez se encuentran entre las mejores de la colección El Club de la Sonrisa, en el podio junto a obras como Mis memorias de Miguel Mihura, El pisito de Rafael Azcona, Historia de la gente de Antonio Mingote o Don Clorato de Potasa de Edgar Neville. Entre sus logros contamos con el retrato de uno de esos personajes que se tornan en paradigmáticos, el escéptico tío Gustavo; la maestría en el manejo de recursos ya clásicos insuflándoles nueva vida; o el poner de manifiesto con una violencia inusitada, temas tabúes en el mundo del humor desde hacía demasiados años. Las macabras sátiras de Chumy Chúmez tendrán, sobre todo, el mérito de restituir el sarcasmo salvaje, ausente desde principios de siglo. 


\section{REFERENCIAS BIBLIOGRÁFICAS:}

Azcona, Rafael (1957), El pisito, Madrid, Taurus.

Chúmez, Chumy (1956), El manzano de tres patas, Madrid, Taurus.

- (1958), Mi tío Gustavo que en gloria esté, Madrid, Taurus.

- (1973), Con la clara y con la yema, Barcelona, Ediciones Península.

- (1986), Yo fui feliz en la guerra, Barcelona, Plaza \& Janés.

- (1988), Ayer casi me muero, Barcelona, Plaza \& Janés.

- (1996), Hacerse un hombre, Madrid, Grupo Unido de Proyectos y Operaciones, S.A.

- (1999), Moderna cartilla de urbanidad, Madrid, Edaf.

- (2000), Cartas de un hipocondriaco a su médico de cabecera, Madrid, Edaf.

- (2001), Del silencio al grito, Madrid, Edaf

- (2003), Vida de Maqueto, Madrid, Algaba Ediciones.

Fernández Escudero, María Ángeles (2011), Chumy Chúmez. El humor y la libertad. Los años del diario Madrid (1967-1971), Madrid, Fundación Diario Madrid.

FonTeS, Ignacio y MenÉndez, Manuel Ángel (2004), El parlamento de papel. Las revistas españolas en la transición democrática, Madrid, APM.

González-Grano de Oro, Emilio (2004), La "Otra" Generación del 27. El "Humor Nuevo" español y "La Codorniz" primera, Madrid, Polifemo.

Hoyo, Mercedes del y Chúmez Chumy (2003), «Freud, el humor y yo», en José Luis Peñalva Abrisqueta y María José Cantalapiedra González (eds.), El humor en los medios de comunicación, Universidad del País Vasco, págs. 127-142.

LLERA, José Antonio (2003), El humor verbal y visual de «La Codorniz», Madrid, CSIC. 
- (2007), «Documentos inéditos sobre "La Ametralladora" y "La Codorniz" de Miguel Mihura», en Juan A. Ríos Carratalá (ed.), «Humor y humoristas en la España del franquismo», Anales de Literatura Española, n. ${ }^{\circ} 19$, Alicante, Universidad de Alicante, pp. 115-135.

Macciuci, Raquel (2016), " "Chumy Chúmez. Una biografía”. Autoficción, testimonio y homenajes», en Diablotexto Digital, 1, páginas, 77-111. En línea: https://ojs.uv.es/index.php/diablotexto/article/view/8857. Último acceso el 23-nov-2018.

Peñalva Abrisqueta, José Luis y Cantalapiedra González, María José (2003), eds., El humor en los medios de comunicación, Universidad del País Vasco.

Ríos Carratalá, Juan A. (2007), ed., «Humor y humoristas en la España del franquismo», Anales de Literatura Española, n. ${ }^{\circ} 19$, Alicante, Universidad de Alicante.

Seaver, Paul W. y Llera, José Antonio (2003), entrevistadores, «Chumy Chúmez. Semblanza y parlamento de un misántropo», en Nueva revista de política, cultura y arte, 87, págs. 102-112.

VV.AA. (2004), Taurus cincuenta años de una editorial, Madrid, Santillana.

Weis Bauer, Samuel Michael (2012), Cincuenta años de Humor Nuevo: La obra de Antonio de Lara Gavilán (1921-1971), Barcelona, Universidad Autónoma de Barcelona. Tesis doctoral.

\section{Materiales audiovisuales:}

Humoristas gráficos y dibujantes de historietas: Chumy Chúmez (2005), Documental de TVE. En línea: http://www.rtve.es/alacarta/videos/humoristas-graficos-y-dibujantes-de-historietas/humoristas-graficos-dibujantes-historietas-chumy-chumez/2778142/ 